\title{
FORMULATION AND EVALUATION OF FLOATING IN SITU GEL OF OMEPRAZOLE MAGNESIUM FOR ORAL DRUG DELIVERY SYSTEM
}

\author{
ANKIT SONI*, MAHESH KUMAR KATARIA \\ Department of Pharmaceutics, Seth G. L. Bihani S. D. College of Technical Education, Gagan Path, Sri Ganganagar, Rajasthan, India. \\ Email: pharmacy.ankitsoni@gmail.com
}

Received: 30 May 2021, Revised and Accepted: 05 July 2021

\begin{abstract}
Objective: Omeprazole magnesium is indicated for the treatment of erosive esophagitis associated with gastroesophageal reflux disease. It is one of the highly prescribed proton pump inhibitor in the management of peptic ulcer diseases. The therapeutic concentration of a drug in blood can be maintained for a prolonged period of time by administering it in the form of in situ floating gel dosage form. Omeprazole magnesium undergoes degradation at a low $\mathrm{pH}$ of the esophagus and stomach; it is therefore given as in situ gel, so, there is minimum contact with acidic $\mathrm{pH}$.
\end{abstract}

Methods: Omeprazole magnesium suspension prepared using various polymers and floating agents in varying concentrations. Several evaluation tests including dissolution test to ensure the release of the drug from formulation by in vitro technique, color and homogeneity, in vitro floating duration, in vitro gelling capacity, drug content determination, $\mathrm{pH}$ of the formulation, and floating lag time were studied.

Results: All formulations demonstrated good Fourier-transform infrared compliance and no interaction between drug, polymer, and other excipients. The study's findings show that the formulation F6 showed the best results.

Conclusion: The developed formulation was a viable alternative conventional solution by virtue of its ability to enhance bioavailability through its longer gastric residence time and ability to sustain drug release as well as the advantage of floating and $\mathrm{pH}$ which minimize the degradation of omeprazole magnesium which is easily degraded by acidic environment

Keywords: In situ gel, Gastroesophageal reflux disease, omeprazole magnesium, Polymers, In vitro floating duration, In vitro gelling capacity bioavailability, Gastric resident time.

(C) 2021 The Authors. Published by Innovare Academic Sciences Pvt Ltd. This is an open access article under the CC BY license (http://creativecommons.org/ licenses/by/4.0/) DOI: http://dx.doi.org/10.22159/ajpcr.2021v14i9.42231. Journal homepage: https://innovareacademics.in/journals/index.php/ajpcr

\section{INTRODUCTION}

Floating systems are low-density systems with sufficient buoyancy to float over the gastric contents without affecting the gastric emptying rate for a prolonged period of time. While the system is floating on the gastric contents, the drug is released slowly at the desired rate from the system [1].

Floating system results in an increased gastric retention time and a better control of the fluctuations in plasma drug concentration. Minimal gastric content is required to allow proper achievement of the buoyancy retention principle and a minimal level of floating force $(F)$ is also required to keep the dosage form reliably buoyant on the surface of the meal. Formulation of gastro retentive in situ gel system involves the use of gelling agent which can form a stable sol/suspension system to contain the dispersed drug and other excipients. The gelling of this sol/suspension system is achieved in gastric environment, triggered by ionic complexation due to change in $\mathrm{pH}$ [2]

Gastroesophageal reflux is the involuntary movement of gastric contents to the esophagus (Fig. 1). Gastroesophageal reflux is a normal physiological process that occurs several times a day without symptoms or damage of the esophageal mucosa in most otherwise healthy individuals. Gastroesophageal reflux disease is a condition in which reflux of gastric contents into the esophagus produces frequent or severe symptoms that negatively affect the individual's quality of life or result in damage to esophagus, pharynx, or the respiratory tract [3].

Omeprazole magnesium (Fig. 2) is a benzimidazole with selective and reversible proton pump inhibition activity. It forms a stable disulfide bond with the sulfhydryl group of the hydrogen-potassium $(\mathrm{H}+-\mathrm{K}+)$
ATPase found on the secretory surface of parietal cells, thereby inhibiting the final transport of hydrogen ions (through exchange with potassium ions) into the gastric lumen and suppressing gastric acid secretion [4]

\section{METHODS}

Omeprazole magnesium was kindly provided by $\mathrm{Dr}$ Reddy's Laboratories, Hyderabad, sodium carbonate sodium alginate, methyl paraben, and propyl paraben were procured from Arora and company, Delhi, Sodium citrate and Hydrochloric Acid form Central Drug House (P) Ltd., New Delhi, Calcium chloride from Loba Chemicals, Mumbai. All chemical and reagents used were of analytical grade. De-ionized water was used for the complete study.

\section{Preformulation studies}

Preformulation studies required to ensure the development of a stable as well as therapeutically effective and safe dosage form. These studies focus on the physicochemical properties of the drug that could affect performance and development of an efficacious dosage form.

\section{Description of drug}

Organoleptic properties of drug, that is, color, odor, and taste were observed.

\section{Identification of drug}

- UV spectrophotometric analysis of drug Ultraviolet absorption in the range $200-400 \mathrm{~nm}$ of a $100 \mu \mathrm{g} / \mathrm{ml}$ solution of the drug in $0.1 \mathrm{~N} \mathrm{HCl}$ was determined [5].

- Fourier-transform infrared (FTIR) analysis of drugs 
The FTIR analysis of the sample was carried out for qualitative compound identification in ATR based Brukers Tensor 27 instrument. The samples were kept at room temperature (initially) and at $50^{\circ} \mathrm{C}$ for 15 days before study.

\section{Analytical estimation of drug}

- Determination of absorption maxima ( $\lambda$ max)/wavelength maxima

The standard stock solution of omeprazole magnesium was prepared by dissolving $10 \mathrm{mg}$ of drug in $0.1 \mathrm{~N} \mathrm{HCl}$ in $100 \mathrm{ml}$ volumetric flask. Stock solution of omeprazole magnesium was further diluted in $0.1 \mathrm{~N} \mathrm{HCl}$ to get standard solution of $100 \mu \mathrm{g} /$ $\mathrm{ml}$. The resulting solution was then scanned between 200 and $400 \mathrm{~nm}$ UV visible spectrophotometer (shimadzu 1700).

- Preparation of standard calibration curve of Omeprazole magnesium Omeprazole magnesium (10 mg) was dissolved in (0.1 N HCl, pH 1.2) and volume was made up to $100 \mathrm{ml}$ in $100 \mathrm{ml}$ volumetric flask. This solution $(100 \mu \mathrm{g} / \mathrm{ml})$ was further diluted

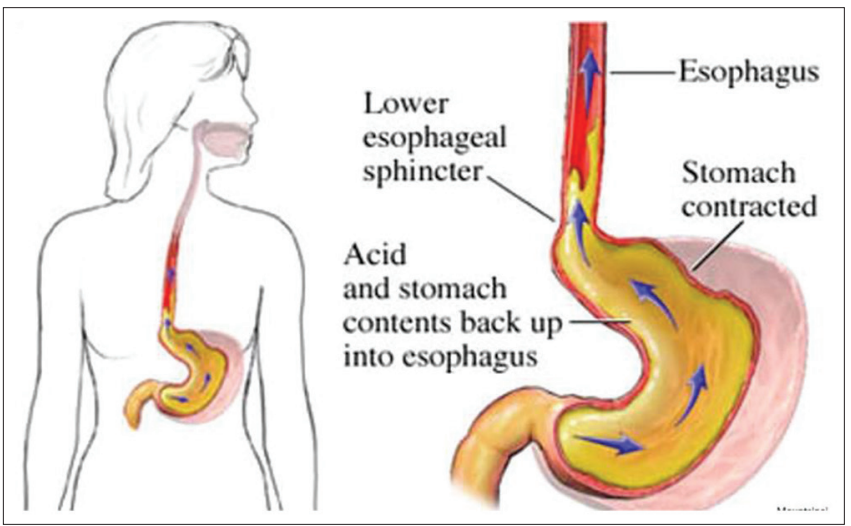

Fig. 1: Gastroesophageal reflux disease

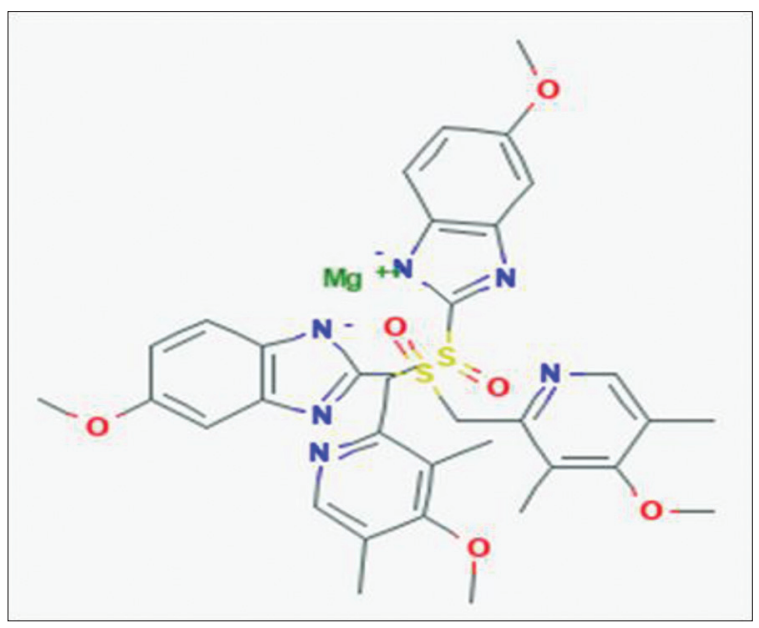

Fig. 2: Structure of omeprazole magnesium with $(0.1 \mathrm{~N} \mathrm{HCl}, \mathrm{pH} 1.2)$ to obtain solution of $10-50 \mu \mathrm{g} / \mathrm{ml}$. The absorbance of each solution was measured at $\lambda_{\max } 348.5 \mathrm{~nm}$ using UV spectrophotometer. The standard curve was obtained by plotting absorbance versus concentration $(\mu \mathrm{g} / \mathrm{ml})$.

\section{- Melting point determination}

Melting point of omeprazole magnesium was determined using melting point apparatus. The pre-sealed capillary filled by the small amount of drug, the capillary, and thermometer placed in melting point apparatus. The temperature noted when the drug starts to melt and till complete melt. The standard melting point is between 199 and $201^{\circ} \mathrm{C}$ (USP, 2005)

- Solubility determination

For quantitative solubility studies, known amount of drug $(10 \mathrm{mg})$ was suspended in solvents, that is, water, $0.1 \mathrm{~N}$ $\mathrm{HCl}$. The solutions were stirred for $48 \mathrm{~h}$ on magnetic stirrer under thermostat. To separate phases, the solutions were left to sediment for $24 \mathrm{~h}$ under thermostat circumstances. The absorption of diluted aliquots was measured with UV spectrophotometer $[6,7]$

- Drug-polymer compatibility study

The possible interaction between the drug and excipients was studied by infra-red spectroscopy. The equal quantity of drug and excipient was kept at $50^{\circ} \mathrm{C}$ for 15 days and the same quantity of both to prepare fresh immediate samples was taken and spectra were observed for compatibility [8].

\section{Formulation and evaluation of in situ gel}

\section{Fabrication of omeprazole magnesium in situ gel}

Omeprazole magnesium suspension prepared using various polymers and floating agents. Sodium alginate solution of different concentrations (0.50-1.5 g) prepared in deionized water containing sodium citrate $(0.25 \mathrm{~g})$ and calcium chloride $(0.016 \mathrm{~g})$. The sodium alginate dispersed in deionized water, heated up to $90^{\circ} \mathrm{C}$ with stirring continuously on magnetic stirrer and then cooled below $40^{\circ} \mathrm{C}$ various concentrations of calcium carbonate and drug was added after cooling the solution below $40^{\circ} \mathrm{C}$ with continuous stirring to form uniform dispersion. Total nine formulations (Table 1) were prepared and evaluated [9].

\section{Evaluation and characterization of floating in situ gel}

Physical appearance

Sodium alginate based in situ suspension was visually checked for their clarity, that is, color, homogeneity.

pH of in situ solution

The $\mathrm{pH}$ was measured for sodium alginate based in situ suspension using a $\mathrm{pH}$ meter. The $\mathrm{pH}$ of each suspension was determined in triplicates.

In vitro gelling capacity

To evaluate the formulations for their in vitro gelling capacity by visual method, suspension of in situ gel forming drug delivery system was prepared. The in vitro gelling capacity of formulations was measured by

Table 1: Formulae of formulation

\begin{tabular}{|c|c|c|c|c|c|c|c|c|c|}
\hline Formulation code Ingredient $\downarrow$ & F1 & F2 & F3 & F4 & F5 & F6 & F7 & F8 & F9 \\
\hline Omeprazole magnesium (g) & 0.100 & 0.100 & 0.100 & 0.100 & 0.100 & 0.100 & 0.100 & 0.100 & 0.100 \\
\hline Sodium alginate $(\mathrm{g})$ & 0.50 & 1.0 & 1.5 & 0.50 & 1.0 & 1.5 & 0.50 & 1.0 & 1.5 \\
\hline Tri-sodium citrate $(\mathrm{g})$ & 0.25 & 0.25 & 0.25 & 0.25 & 0.25 & 0.25 & 0.25 & 0.25 & 0.25 \\
\hline Calcium chloride (g) & 0.016 & 0.016 & 0.016 & 0.016 & 0.016 & 0.016 & 0.016 & 0.016 & 0.016 \\
\hline Calcium carbonate (g) & 0.25 & 0.25 & 0.25 & 0.75 & 0.75 & 0.75 & 1.5 & 1.5 & 1.5 \\
\hline Methyl paraben (g) & 0.18 & 0.18 & 0.18 & 0.18 & 0.18 & 0.18 & 0.18 & 0.18 & 0.18 \\
\hline Propyl paraben (g) & 0.2 & 0.2 & 0.2 & 0.2 & 0.2 & 0.2 & 0.2 & 0.2 & 0.2 \\
\hline Water q.s. (ml) & 50 & 50 & 50 & 50 & 50 & 50 & 50 & 50 & 50 \\
\hline
\end{tabular}


placing $5 \mathrm{ml}$ of the gelation solution $(0.1 \mathrm{~N} \mathrm{HCl})$ in a $15 \mathrm{ml}$ borosilicate glass test tube and maintained at $37 \pm 1^{\circ} \mathrm{C}$ temperature. $1 \mathrm{ml}$ of formulation suspension was transferred slowly by placing the pipette at surface of fluid in test tube. As the suspension comes in contact with gelation solution, it immediately converted into stiff gel like structure. The gelling capacity of solution was evaluated on the basis of stiffness of formed geland time period for which formed gel remains as such. The in vitro gelling capacity was graded in three categories on the basis of gelation time and time period for which formed gel remains [10].

$(+)$ Gels after few minutes, dispersed rapidly, $(++)$ Gelation immediate remains for $12 \mathrm{~h},(+++)$ Gelation immediate remains for more than $12 \mathrm{~h}$.

\section{In vitro floating duration}

The in vitro floating study was determined using USP dissolution apparatus II having $900 \mathrm{ml}$ of Hydrochloric acid $(0.1 \mathrm{~N})$. The temperature of the dissolution medium was kept at $37^{\circ} \mathrm{C}$ and $10 \mathrm{ml}$ prepared in situ gel formulations were transferred. Time for the formulation took to emerge on the medium surface (floating lag time) and the time the formulation constantly floated on the dissolution medium surface (duration of floating) was noted.

\section{Floating lag time}

The floating lag time is defined as time taken by the gel to reach the top from bottom of the dissolution flask. The floating lag time is determined by visual inspection in a USP (Type II) dissolution test apparatus containing $900 \mathrm{ml}$ of $0.1 \mathrm{~N} \mathrm{HCl}$ at $37^{\circ} \mathrm{C}$.

\section{Determination of drug content}

The $5 \mathrm{ml}$ of the suspension was added to $100 \mathrm{ml}(0.1 \mathrm{~N} \mathrm{HCl}, \mathrm{pH} 1.2)$ solution and stirred for an hour on magnetic stirrer. The suspension was filtered and the drug concentration was determined using UV-visible spectrophotometer at $\lambda_{\max } 348.5 \mathrm{~nm}$ against a suitable blank solution [11].

\section{In vitro drug release study}

The release of omeprazole magnesium from sustained release suspension was determined using dissolution apparatus I (basket covered with muslin cloth) at $50 \mathrm{rpm}$. The rotation speed was slow enough to avoid breaking of gelled formulation and maintained at mild agitation conditions as remains at in vivo. The $900 \mathrm{ml}$ dissolution medium of $0.1 \mathrm{~N} \mathrm{HCl}$ was maintained at $37^{\circ} \mathrm{C} \pm 0.5^{\circ} \mathrm{C}$ temperature. A sample $(5 \mathrm{ml})$ of solution was withdrawn from the dissolution apparatus at $0 \mathrm{~min}, 15 \mathrm{~min}, 30 \mathrm{~min}, 45 \mathrm{~min}, 60 \mathrm{~min}, 1 \mathrm{~h}, 2 \mathrm{~h}, 3 \mathrm{~h}, 4 \mathrm{~h}, 5 \mathrm{~h}$, $6 \mathrm{~h}, 8 \mathrm{~h}, 10 \mathrm{~h}$, and $12 \mathrm{~h}$ of dissolution. The samples were filtered through Whatman filter paper and analyzed using UV method. Cumulative percentage of drug release was calculated [2].

\section{Selection of best formulations}

On the basis of various evaluation parameters, namely floating lag time and in vitro release study two formulations were found to be optimum for the further study, that is, F3 and F6. These formulations were formulated and evaluated for physical appearance, $\mathrm{pH}$ of in situ solution, drug content, in vitro floating duration, floating lag time, and in vitro drug release study of the formulations. On the basis of dissolution, F3 was found to be having less drug release as well as drug content as compared to F6, thus F6 was selected as the final formulation.

\section{Study of marketed formulation and its comparison with final} formulation

OMEZ Insta $20 \mathrm{mg}$ by Dr. Reddy's was the available marketed preparation. This product was taken as the standard and was compared with the final formulation with respect to evaluating parameters, namely, in vitro drug release, drug content, release kinetics, similarity factor, and difference factor.

\section{Drug content uniformity}

The entire sachet was dissolved in $100 \mathrm{ml} 0.1 \mathrm{~N} \mathrm{HCl}$ and kept for $2 \mathrm{~h}$. The solution was filtered and filtrate $(5 \mathrm{ml})$ was diluted to $10 \mathrm{ml}$.
Absorbance of the resulting solution was measured with a UV-Visible spectrophotometer UV-1700 (Shimadzu, Japan) at $\lambda_{\max } 348.5 \mathrm{~nm}$.

\section{In vitro drug release}

A USP dissolution apparatus type II was employed to study in vitro drug release. The dissolution medium used was $900 \mathrm{~mL}$ of $0.1 \mathrm{~N} \mathrm{HCl}$, $37 \pm 0.5^{\circ} \mathrm{C}$ temperature at stirring rate $50 \mathrm{rpm}$.

\section{Kinetic modeling}

Model independent methods

A simple model independent approach uses a difference factor (f1) and a similarity factor (f2) to compare dissolution profiles.

a) Difference factor

The difference factor calculates the percentage difference between the two curves at each time point and is a measurement of the relative error between the two curves. Reference values are given in Table 2. It is calculated by formulae:

$f 1=\Sigma(\mathrm{Rt}-\mathrm{Tt}) / \Sigma R t \times 100$

b) Similarity factor

The similarity factor is a logarithmic reciprocal square root transformation of the sum of squared error and is a measurement of the similarity in the percentage dissolution between the two curves, that is, test - reference. It represents closeness of two comparative formulations. Reference values are given in Table 2 . It is calculated by formulae:

$$
f_{2}=50 \times \log \left\{\left[1+\frac{1}{n} \sum_{t=1}^{n}\left(R_{1}-T_{1}\right)^{2}\right]^{-5} \times 100\right\}
$$

\section{Model dependent methods}

Model dependent methods are based on different mathematical function, which describes the dissolution profile. The dissolution profiles are evaluated depending on the derived model parameters. The model dependent approach included zero order, first order, Higuchi, and Korsmeyer-Peppas model.

Release kinetics described the overall release of the drug from the dosage forms. As qualitative and quantitative changes in a formulation may alter drug release and in vivo performance, developing tools that facilitate products development by reducing the necessity of bio-studies is always desirable. In this regard, the use of in vitro drug dissolution data to predict in vivo bio-performance can be considered as the rational development of controlled release formulations.

Data obtained from the in vitro release studies were fitted to various model dependent kinetics equations such as zero order, first order, Higuchi model, and Korsmeyer-Peppas model which are shown below.

Zero order model $Q_{t}=Q_{0}+K_{0} t$

First order model $\log \mathrm{C}=\log \mathrm{C}_{\mathrm{o}}-\mathrm{Kt} / 2.303$

Higuchi model $\mathrm{Q}=\mathrm{K}_{\mathrm{H}} \times \mathrm{t}^{1 / 2}$

Korsmeyer-peppas model $\mathrm{Q} / \mathrm{Q}_{0}=\mathrm{Kt}^{\mathrm{n}}$

Where, $K_{0}$ to $K_{H}$ were release rate constants, Q/Qo was fraction of drug released at time $\mathrm{t}, \mathrm{K}$ was a constant and $\mathrm{n}$ was diffusion constant that indicates general operating release mechanism. For Fickian (diffusion controlled), $n \leq 0.5$; for non Fickian release, " $n$ " value is in between 0.5

Table 2: Comparison of dissolution profiles

\begin{tabular}{lll}
\hline $\mathbf{f 1}$ & $\mathbf{f 2}$ & Inference \\
\hline 0 & 100 & Dissolution profiles are identical \\
$\leq 15$ & $\geq 50$ & Similarity or equivalence of two profiles \\
\hline
\end{tabular}


to 1.0; for zero order release, $n=1$; for super case transport II, $n>1.040$. Based on the slope and the $r^{2}$ values obtained from the above models the mechanism of drug release was decided [12,13].

\section{RESULTS AND DISCUSSION}

\section{Preformulation studies}

Description of drug: The observed parameters are reported in Table 3.

\section{Identification of drug}

a) UV spectrophotometric analysis of drug

Photometric spectrum shows by data analysis that the there is only one significant peak which is clearly distinguishable and obtained at $348.5 \mathrm{~nm}$. Hence, absorption maxima $\left(\lambda_{\max }\right)$ of omeprazole magnesium are meant to be $348.5 \mathrm{~nm}$.

b) FTIR spectrum method

Drug and polymers identified by IR spectrum method which are compared with its standard IR given in pharmacopeia. These IR spectra given below (Table 4) shown that the peaks obtained in these spectra (Fig. 4) are similar to that given in standard (Fig. 3).

\section{Analytical methods of estimation}

Analytical methods obey Beer's law and found suitable for the study. Standard calibration curve of omeprazole magnesium was prepared in $0.1 \mathrm{~N} \mathrm{HCl}$.

Determination of absorption maxima $\left(\lambda_{\max }\right) /$ wavelength maxima The $\lambda_{\max }$ of given sample of omeprazole magnesium (348.5 nm) and standard value ( $345.42 \mathrm{~nm}$ ) found to be similar hence drug is omeprazole magnesium.

Preparation of standard calibration curve of omeprazole magnesium The standard curve was obtained by plotting absorbance versus concentration ( $\mu \mathrm{g} / \mathrm{ml}$; Table 5).

\section{Solubility determination}

Omeprazole magnesium was very slightly soluble in water $(1 \mathrm{mg}$ in $100 \mathrm{ml}$ ), readily soluble in $0.01 \mathrm{~N} \mathrm{HCl}$ (10 mg in $100 \mathrm{ml}$ ).

\section{Melting point determination}

Melting point of omeprazole magnesium was found to be in the range of $199-201^{\circ} \mathrm{C}$.

Table 3: Description of drug

\begin{tabular}{lll}
\hline S. No. & Properties & Inference \\
\hline 1. & Color & White \\
2. & Odor & Odorless \\
3. & Taste & Bitter \\
\hline
\end{tabular}

Table 4: Interpretation of infrared spectrum of omeprazole magnesium

\begin{tabular}{llcc}
\hline S. No & Peaks (cm-1) & & \\
\hline & Absorbance assignment & Reported & Observed \\
\hline 1 & C=C aromatic stretching & 1591 & 1591 \\
2 & methyl C-H stretching & 2944 & 2931 \\
3 & out of plane bending of aromatic & 850 & 843.97 \\
& ring bonds & & \\
4 & symmetrical C-H bending & 1410 & 1412.35 \\
5 & symmetrical C-H bending & 1477 & 1483.15 \\
6 & -C-O-C- asymmetrical stretching & 1034 & 1065.56 \\
7 & strong -S=O stretching, & 1014 & 1011.22 \\
8 & C=N hetero aromatic stretching of & 1613 & 1613 \\
& pyridine & & \\
\hline
\end{tabular}

Drug-excipient compatibility study

FTIR spectrum shows the peaks of pure drug sample and polymers as compared to standard drug samples, that is, no chemical reaction occurs between polymers and drug samples (Table 6).

\section{Evaluation of prepared in situ gels}

The color, homogeneity, $\mathrm{pH}$, gelling capacity, floating time, floating lag time, and drug content observed are as following in Table 7.

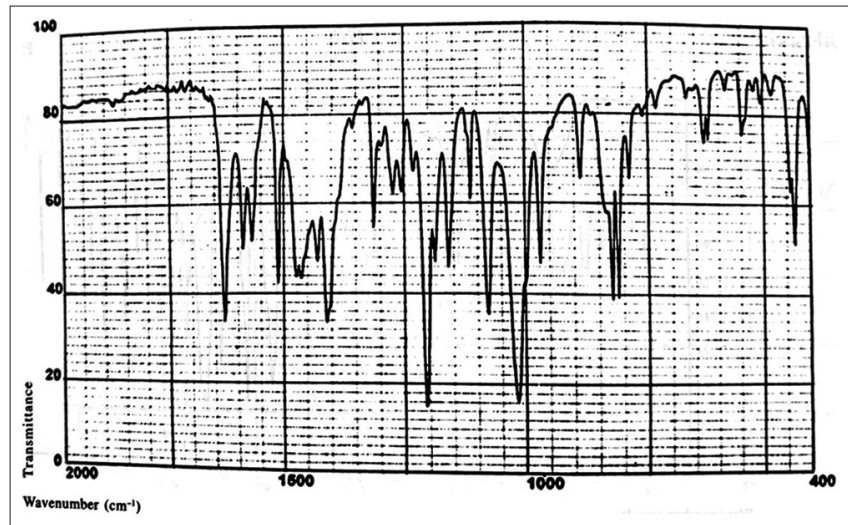

Fig. 3: Standard Fourier-transform infrared spectrum of omeprazole magnesium (reference)

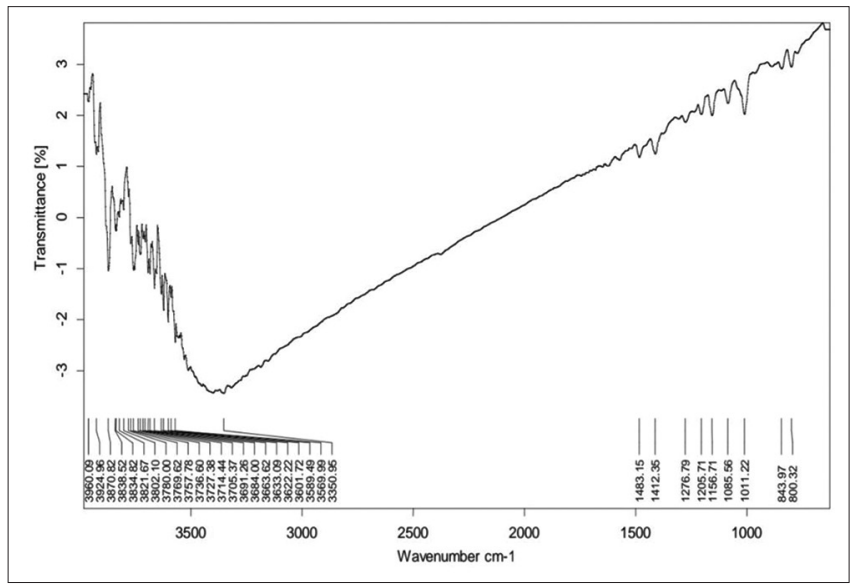

Fig. 4: Fourier-transform infrared of omeprazole magnesium (test)

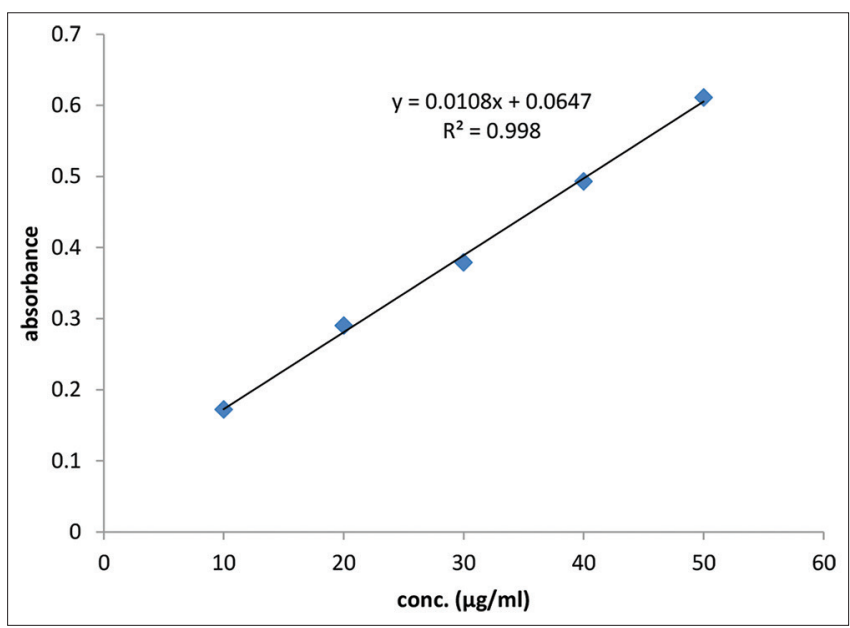

Fig. 5: Calibration curve of omeprazole magnesium 


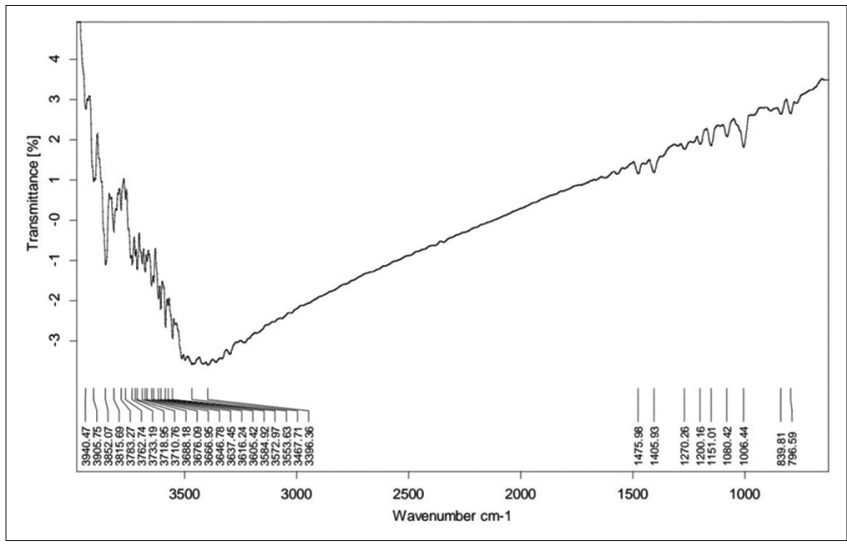

Fig. 6: Fourier-transform infrared spectrum of omeprazole magnesium (immediate)

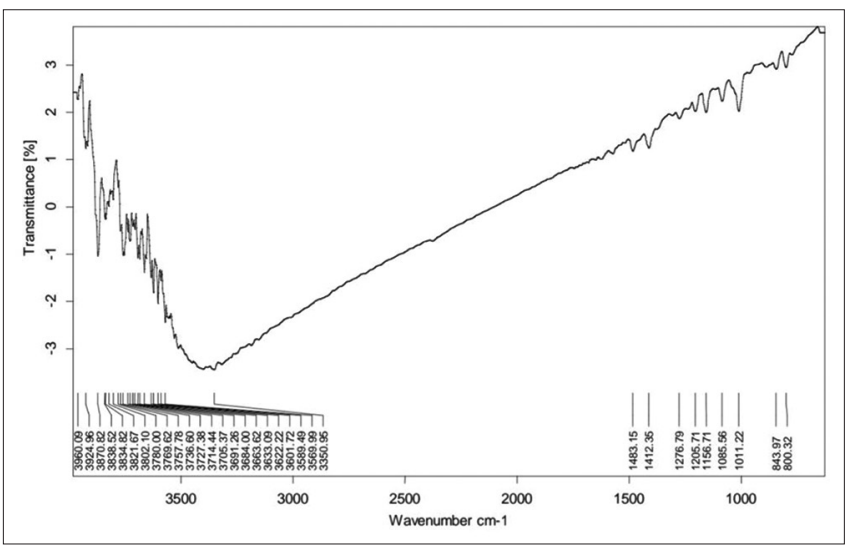

Fig. 7: Fourier-transform infrared spectrum of omeprazole magnesium (after 15 days)

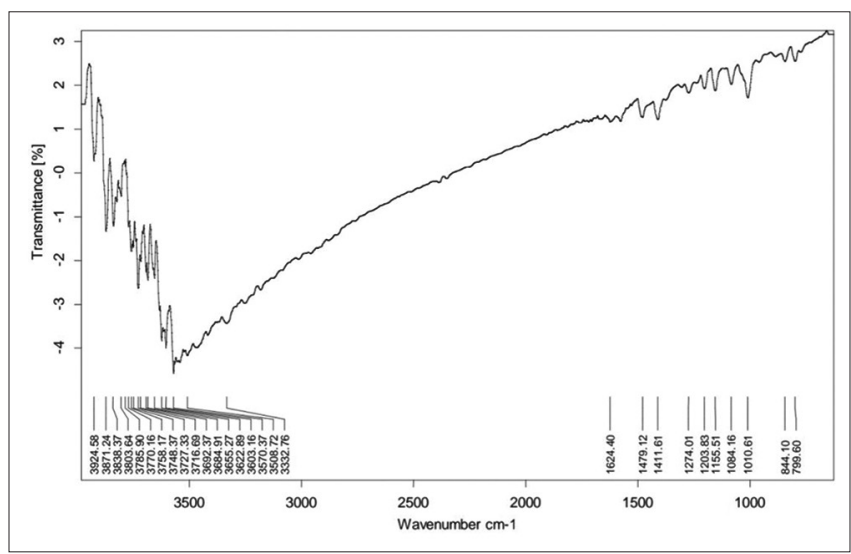

Fig. 8: Fourier-transform infrared spectrum of omeprazole magnesium with sodium alginate (immediate)

In vitro drug release study

The dissolution profile is presented in Table 8 given below. The rate release profile was plotted as the percentage linear drug release versus time. This showed that drug releases increases with increase in time. The dissolution data obtained were plotted as cumulative percentage release versus time.

It was observed that F3 and F6 showed higher release and both were again reformulated and evaluated in the similar manner and it was found that F6 was better in terms of drug release and stability, so, it was

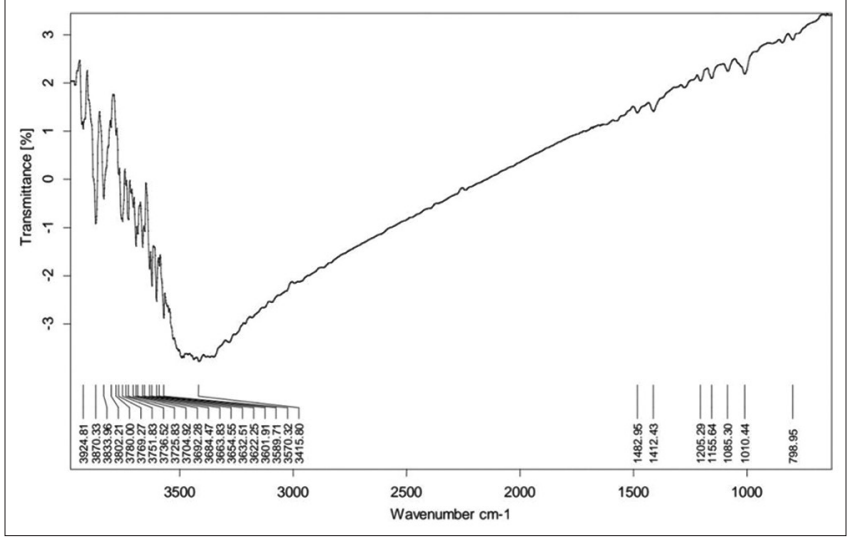

Fig. 9: Fourier-transform infrared spectrum of omeprazole magnesium with sodium alginate (after 15 days)

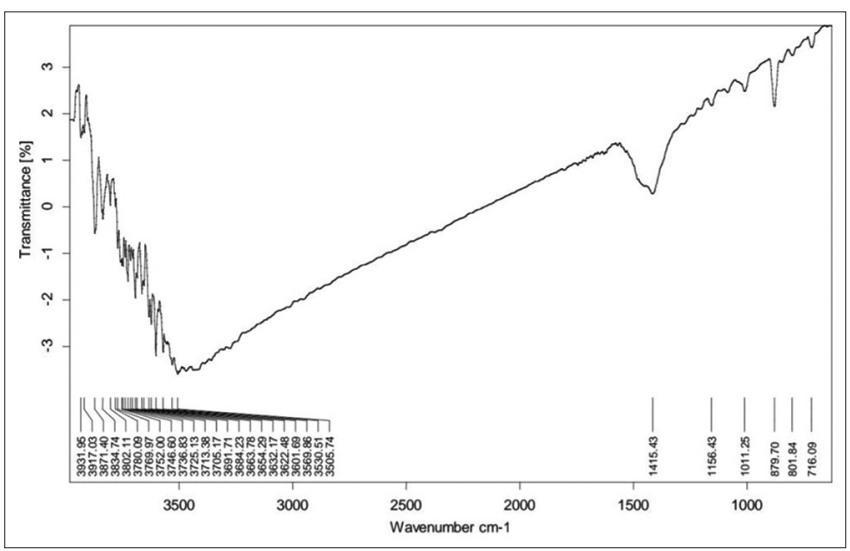

Fig. 10: Fourier-transform infrared spectrum of omeprazole magnesium with calcium carbonate (immediate)

Table 5: Absorbance of omeprazole magnesium

\begin{tabular}{ll}
\hline Conc. $(\mathbf{m c g} / \mathbf{m l})$ & Abs* (avg.) \\
\hline 10 & 0.172 \\
20 & 0.290 \\
30 & 0.379 \\
40 & 0.493 \\
50 & 0.611 \\
\hline
\end{tabular}

*Average of three readings

Table 6: Quantity used for drug and polymer identification and results

\begin{tabular}{|c|c|c|c|c|c|}
\hline \multirow{3}{*}{$\begin{array}{l}\text { S. } \\
\text { No. }\end{array}$} & \multirow{3}{*}{$\begin{array}{l}\text { API and } \\
\text { excipients }\end{array}$} & \multirow{3}{*}{$\begin{array}{l}\text { Quantity } \\
\text { per vial } \\
\text { (mg) }\end{array}$} & \multicolumn{2}{|c|}{ No. of Vials } & \multirow{3}{*}{$\begin{array}{l}\text { Results } \\
\text { (complies or } \\
\text { not) }\end{array}$} \\
\hline & & & Initial & $50^{\circ} \mathrm{C}$ & \\
\hline & & & & $\begin{array}{l}\text { After } \\
15 \text { days }\end{array}$ & \\
\hline 1 & $\begin{array}{l}\text { Omeprazole } \\
\text { magnesium }\end{array}$ & 10 & 1 & 1 & Complies \\
\hline 2 & $\begin{array}{l}\text { Omeprazole } \\
\text { magnesium and } \\
\text { sodium alginate }\end{array}$ & 10 & 1 & 1 & Complies \\
\hline 3 & $\begin{array}{l}\text { Omeprazole } \\
\text { magnesium } \\
\text { and calcium } \\
\text { carbonate }\end{array}$ & 10 & 1 & 1 & Complies \\
\hline
\end{tabular}


Table 7: Physicochemical properties of all formulation

\begin{tabular}{|c|c|c|c|c|c|c|c|}
\hline Formulation code & Color & Homogeneity & pH & Gelling capacity & Floating time (h) & Floating lag time (s) & Drug content \\
\hline F1 & White & + & $8 \pm 0.5$ & + & 10 & 8 & 94.03 \\
\hline $\mathrm{F} 2$ & White & ++ & $8 \pm 0.5$ & ++ & 11 & 11 & 92.04 \\
\hline F3 & Off White & ++ & $8 \pm 0.5$ & +++ & $>12$ & 6 & 97.30 \\
\hline $\mathrm{F} 4$ & Off White & + & $8 \pm 0.5$ & ++ & 9 & 8 & 96.10 \\
\hline F5 & White & ++ & $8 \pm 0.5$ & + & $>12$ & 7 & 97.10 \\
\hline F6 & Off White & ++ & $8 \pm 0.5$ & +++ & $>12$ & 6 & 98.20 \\
\hline F7 & White & + & $8 \pm 0.5$ & ++ & 10 & 8 & 93.60 \\
\hline F9 & Off White & ++ & $8 \pm 0.5$ & + & 11.5 & 10 & 92.50 \\
\hline
\end{tabular}

Table 8: Results of in vitro drug release study of all formulation

\begin{tabular}{|c|c|c|c|c|c|c|c|c|c|}
\hline Time (min.) & F1 & F2 & F3 & F4 & F5 & F6 & F7 & F8 & F9 \\
\hline 5 & 3.96 & 6.48 & 3.60 & 0.72 & 0.36 & 9.00 & 5.04 & 6.12 & 7.56 \\
\hline 10 & 11.18 & 11.56 & 9.74 & 3.96 & 3.24 & 11.21 & 7.59 & 10.11 & 11.20 \\
\hline 15 & 15.20 & 13.42 & 17.35 & 12.62 & 10.82 & 13.79 & 10.87 & 15.21 & 16.10 \\
\hline 30 & 20.69 & 18.53 & 19.97 & 17.01 & 14.84 & 18.91 & 13.81 & 17.45 & 18.73 \\
\hline 45 & 23.68 & 21.88 & 24.04 & 22.14 & 20.68 & 23.33 & 17.13 & 20.43 & 22.44 \\
\hline 60 & 28.49 & 28.12 & 29.57 & 24.06 & 23.68 & 25.98 & 20.46 & 24.50 & 25.44 \\
\hline 90 & 35.49 & 33.67 & 34.05 & 27.08 & 27.05 & 30.08 & 29.57 & 27.88 & 32.06 \\
\hline 150 & 42.37 & 42.35 & 44.92 & 34.59 & 33.84 & 42.33 & 39.27 & 37.20 & 42.16 \\
\hline 180 & 46.92 & 48.34 & 48.40 & 39.46 & 37.27 & 48.32 & 48.12 & 41.01 & 44.19 \\
\hline 240 & 48.62 & 50.76 & 58.02 & 48.32 & 48.27 & 50.74 & 53.43 & 44.47 & 48.75 \\
\hline 300 & 51.76 & 51.76 & 61.22 & 53.98 & 52.49 & 58.93 & 55.88 & 48.67 & 56.93 \\
\hline 360 & 55.28 & 54.91 & 65.87 & 60.03 & 59.97 & 65.73 & 58.70 & 54.33 & 63.72 \\
\hline 420 & 59.53 & 59.53 & 70.18 & 66.11 & 65.70 & 71.49 & 62.25 & 58.58 & 68.38 \\
\hline 480 & 66.69 & 68.13 & 73.08 & 69.71 & 71.45 & 74.39 & 66.19 & 63.94 & 73.79 \\
\hline 540 & 71.73 & 75.33 & 77.79 & 74.40 & 74.36 & 79.11 & 70.50 & 68.24 & 82.11 \\
\hline 660 & 83.31 & 82.27 & 88.72 & 83.49 & 86.34 & 87.53 & 81.72 & 78.00 & 90.94 \\
\hline 720 & 94.56 & 91.34 & 97.11 & 89.34 & 91.84 & 98.79 & 89.71 & 87.05 & 94.30 \\
\hline
\end{tabular}

Table 9: Result of drug content (in duplicates)

\begin{tabular}{lllll}
\hline Formulation code & Marketed & & Final & \\
\hline Drug content $(\%)$ & 92.10 & 91.23 & 97.81 & 97.92 \\
\hline
\end{tabular}

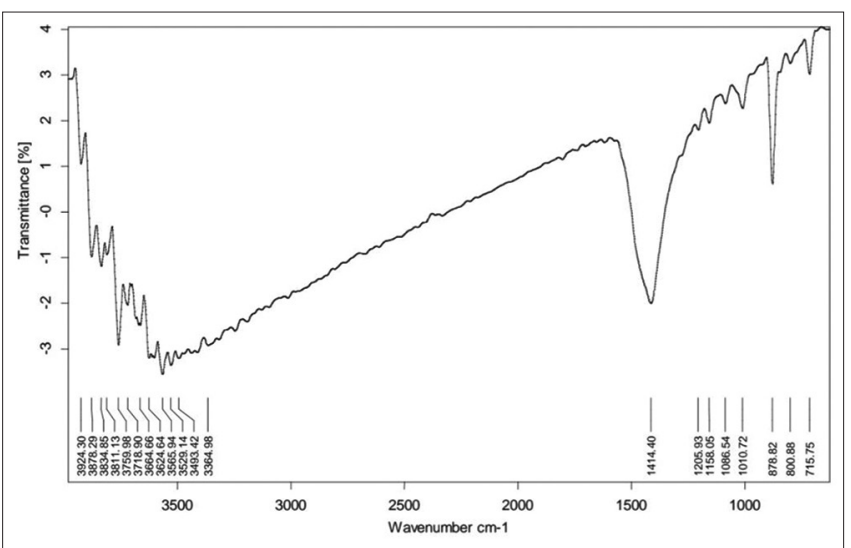

Fig. 11: Fourier-transform infrared spectrum of omeprazole magnesium with calcium carbonate (after 15 days)

selected as the final formulation and compared with available marketed preparation.

Comparative study of final formulation and marketed formulation Drug content: The drug content observed is as following in Table 9.

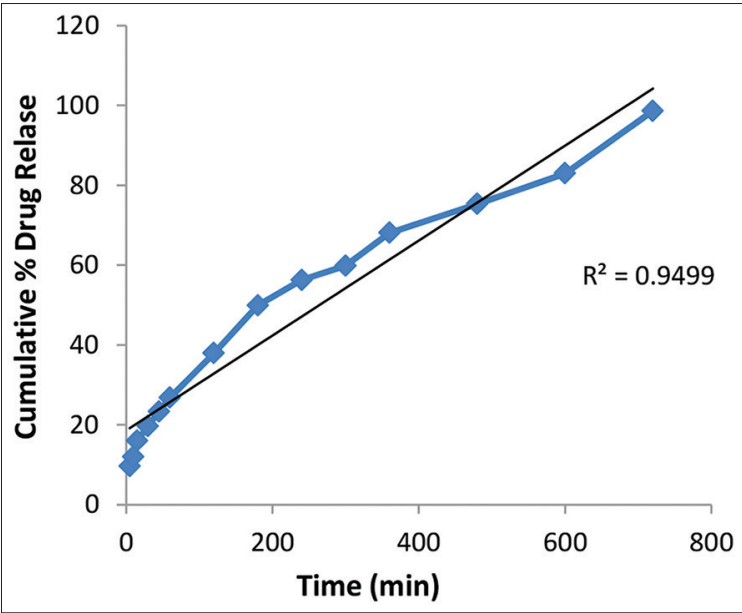

Fig. 12: Zero order equation of final formulation

In vitro drug release

The percentage release versus time value observed for marketed and final formulation in duplicates are mentioned in Table 10.

\section{Kinetic modeling}

Model independent Methods: A simple model independent approach uses a difference factor (f1) and a similarity factor (f2) to compare dissolution profiles.

Similarity factor: The result was found to be 51.31 . Thus, it complies with the standard value (Table 11). 
Table 10: Results of in vitro drug release for final and marketed formulation

\begin{tabular}{|c|c|c|c|c|c|c|c|c|c|c|c|c|c|c|}
\hline Time (min) & 5 & 10 & 15 & 30 & 45 & 60 & 120 & 180 & 240 & 300 & 360 & 480 & 600 & 720 \\
\hline \multirow[t]{2}{*}{ Final formulation (\%CDR) } & 3.7 & 11.94 & 15.96 & 19.65 & 23.31 & 26.79 & 37.91 & 49.88 & 56.27 & 59.81 & 68.05 & 75.29 & 82.96 & 98.63 \\
\hline & 3.76 & 11.93 & 14.88 & 19.64 & 24.79 & 26.73 & 37.84 & 49.80 & 55.47 & 59.73 & 67.25 & 75.20 & 82.87 & 97.82 \\
\hline \multirow[t]{2}{*}{ Marketed (\%CDR) } & 2.91 & 10.4 & 24.9 & 43.1 & 67.8 & 89.7 & & & & & & & & \\
\hline & 3.28 & 10.9 & 26.2 & 43.8 & 69.12 & 90.12 & & & & & & & & \\
\hline
\end{tabular}

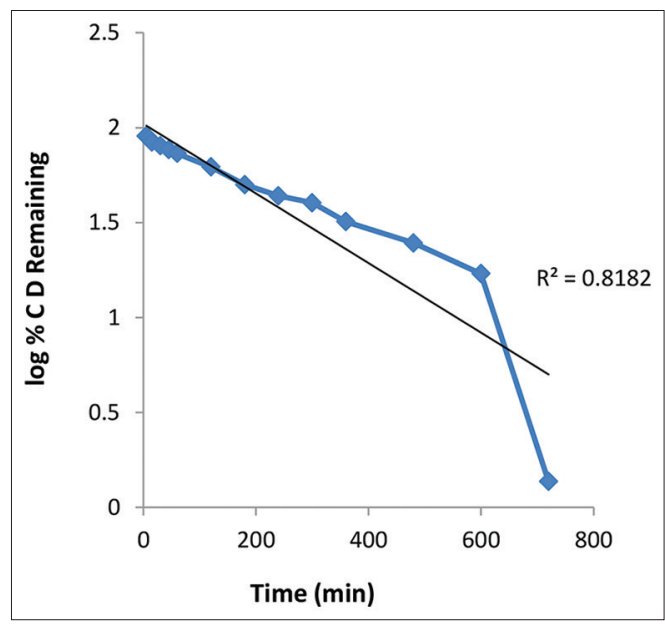

Fig. 13: First order equation of final formulation

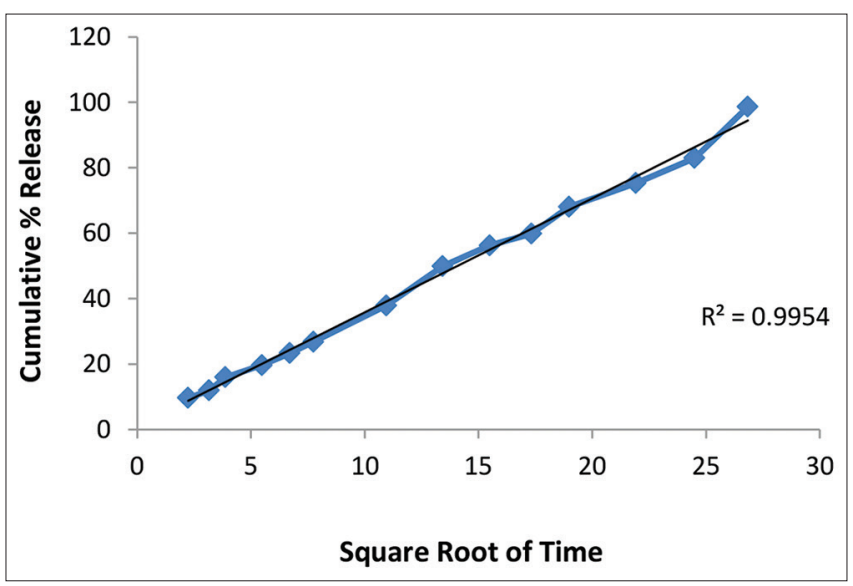

Fig. 14: Higuchi equation of final formulation

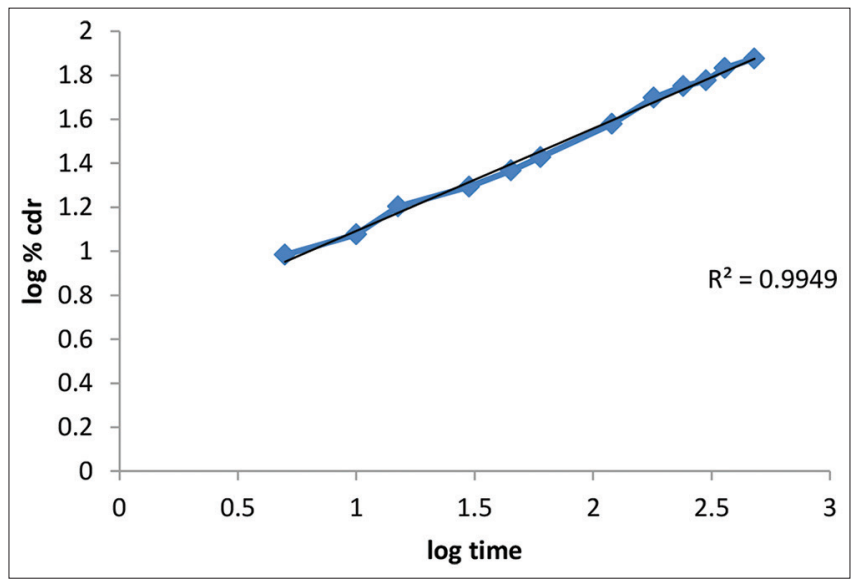

Fig. 15: Korsmeyer-peppas equation of final formulation

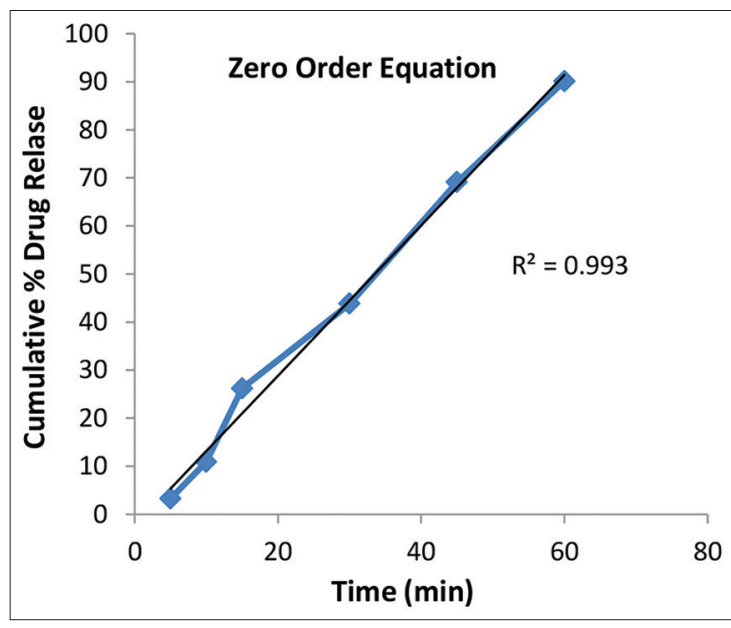

Fig. 16: Zero order equation of marketed formulation

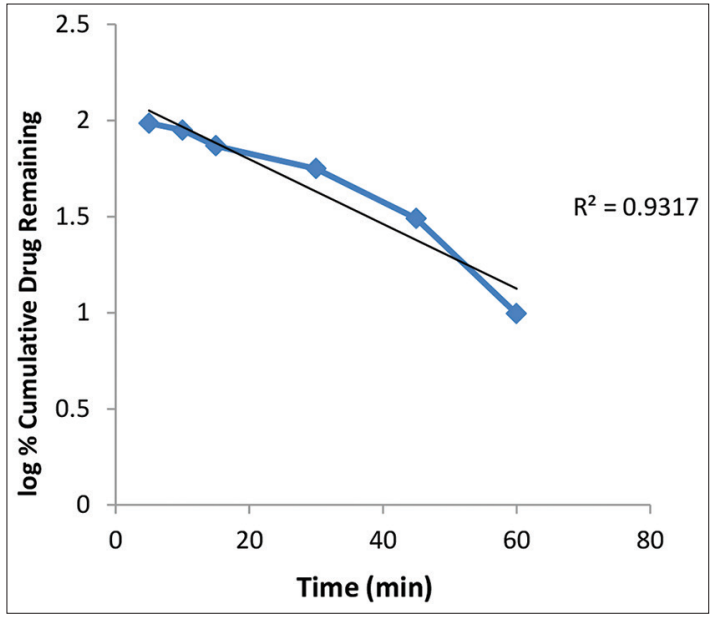

Fig. 17: First order equation of marketed formulation

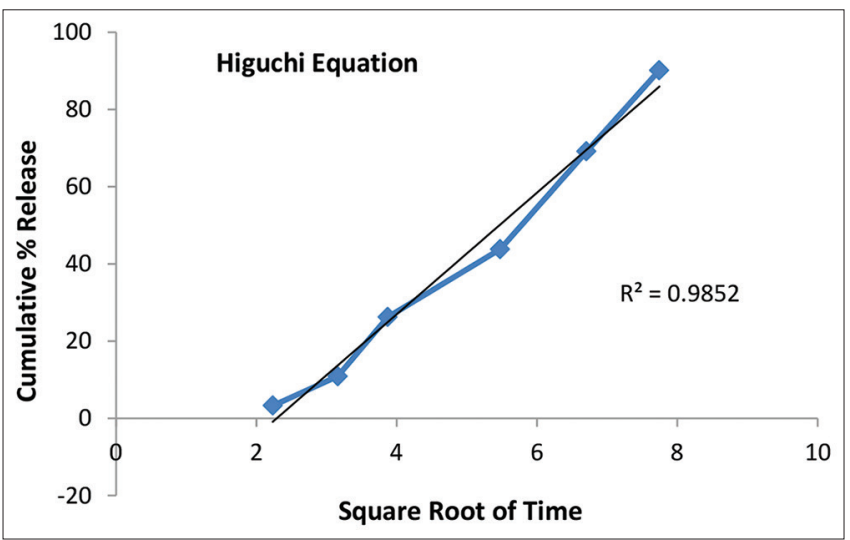

Fig. 18: Higuchi equation of marketed formulation 
Table 11: Results of similarity factor

\begin{tabular}{|c|c|c|c|c|c|}
\hline Time (min) & Test & Reference & Reference - Test & $\log [\{1+(\mathrm{Rt}-\mathrm{Tt}) * 1 / \mathrm{n}\}-0.5]^{* 100}$ & $50+\log [\{1+(\mathrm{Rt}-\mathrm{Tt}) * 1 / \mathrm{n}\}-0.5]$ \\
\hline 5 & 3.7 & 3.28 & -0.42 & 1.5569 & 51.5569 \\
\hline 10 & 11.94 & 10.9 & -1.04 & 1.9826 & 51.9826 \\
\hline 15 & 15.96 & 26.2 & 10.24 & 1.5213 & 51.5213 \\
\hline 30 & 19.65 & 43.8 & 24.15 & 1.1693 & 51.1693 \\
\hline 45 & 23.31 & 69.12 & 45.81 & 0.8947 & 50.8947 \\
\hline 60 & 26.79 & 90.12 & 63.33 & 0.7547 & 50.7547 \\
\hline Average & & & & & 51.31 \\
\hline
\end{tabular}

Table 12: Results of difference factor

\begin{tabular}{|c|c|c|c|c|c|c|}
\hline Time (min) & $\mathbf{R}$ & $\mathbf{T}$ & $\Sigma(\mathrm{R}-\mathrm{T})$ & $\sum \mathbf{R}$ & $\begin{array}{l}\sum(\mathrm{R}-\mathrm{T}) / \\
\sum \mathrm{R}\end{array}$ & $\begin{array}{l}\sum(\mathrm{R}-\mathrm{T}) / \\
\sum \mathrm{R}^{*} \mathbf{1 0 0}\end{array}$ \\
\hline 5 & 3.28 & 3.7 & -0.42 & 3.28 & -1.1280 & -112.8049 \\
\hline 10 & 10.9 & 11.94 & -1.46 & 14.18 & -0.1030 & -10.2962 \\
\hline 15 & 26.2 & 15.96 & 9.2 & 37.1 & 0.2480 & 24.7978 \\
\hline 30 & 43.8 & 19.65 & 34.39 & 70 & 0.4913 & 49.1286 \\
\hline 45 & 69.12 & 23.31 & 69.96 & 112.92 & 0.6196 & 61.9554 \\
\hline 60 & 90.12 & 26.79 & 109.14 & 159.24 & 0.6854 & 68.5381 \\
\hline Average & & & & & & 13.55 \\
\hline
\end{tabular}

Table 13: Release kinetics of final formulation

\begin{tabular}{llllll}
\hline $\begin{array}{l}\text { Time } \\
\text { (min) }\end{array}$ & Sq.rt time & Log time & \%cdr & log \%cdr & $\begin{array}{l}\text { log \% cdr } \\
\text { remaining }\end{array}$ \\
\hline 5 & 2.2361 & 0.6990 & 9.63 & 0.9836 & 1.9560 \\
10 & 3.1623 & 1.0000 & 11.94 & 1.0770 & 1.9448 \\
15 & 3.8730 & 1.1761 & 15.96 & 1.2030 & 1.9245 \\
30 & 5.4772 & 1.4771 & 19.65 & 1.2934 & 1.9050 \\
45 & 6.7082 & 1.6532 & 23.31 & 1.3675 & 1.8847 \\
60 & 7.7460 & 1.7782 & 26.79 & 1.4280 & 1.8646 \\
120 & 10.9545 & 2.0792 & 37.91 & 1.5788 & 1.7930 \\
180 & 13.4164 & 2.2553 & 49.88 & 1.6979 & 1.7000 \\
240 & 15.4919 & 2.3802 & 56.27 & 1.7503 & 1.6408 \\
300 & 17.3205 & 2.4771 & 59.81 & 1.7768 & 1.6041 \\
360 & 18.9737 & 2.5563 & 68.05 & 1.8328 & 1.5045 \\
480 & 21.9089 & 2.6812 & 75.29 & 1.8767 & 1.3929 \\
600 & 24.4949 & 2.7782 & 82.96 & 1.9189 & 1.2315 \\
720 & 26.8328 & 2.8573 & 98.63 & 1.9940 & 0.1367 \\
\hline
\end{tabular}

Table 14: Release kinetics of marketed formulation

\begin{tabular}{llllll}
\hline $\begin{array}{l}\text { Time } \\
\text { (min) }\end{array}$ & Sq.rt time & log time & \%cdr & log \% cdr & $\begin{array}{l}\text { log \%cdr } \\
\text { remaining }\end{array}$ \\
\hline 5 & 2.2361 & 0.6990 & 3.28 & 0.5159 & 1.9855 \\
10 & 3.1623 & 1.0000 & 10.9 & 1.0374 & 1.9499 \\
15 & 3.8730 & 1.1761 & 26.2 & 1.4183 & 1.8681 \\
30 & 5.4772 & 1.4771 & 43.8 & 1.6415 & 1.7497 \\
45 & 6.7082 & 1.6532 & 69.12 & 1.8396 & 1.4897 \\
60 & 7.7460 & 1.7782 & 90.12 & 1.9548 & 0.9948 \\
\hline
\end{tabular}

Table 15: $\mathbf{R}^{2}$ values of different models for final formulation and marketed formulation

\begin{tabular}{lll}
\hline Formulation & Model & $\mathbf{R}^{2}$ value \\
\hline Final & Zero order & 0.949 \\
& First order & 0.818 \\
& Higuchi equation & 0.995 \\
\multirow{3}{*}{ Marketed } & Korsmeyer-Peppas & 0.994 \\
& Zero order & 0.933 \\
& First order & 0.931 \\
& Higuchi equation & 0.985 \\
& Korsmeyer-Peppas & 0.967 \\
\hline
\end{tabular}

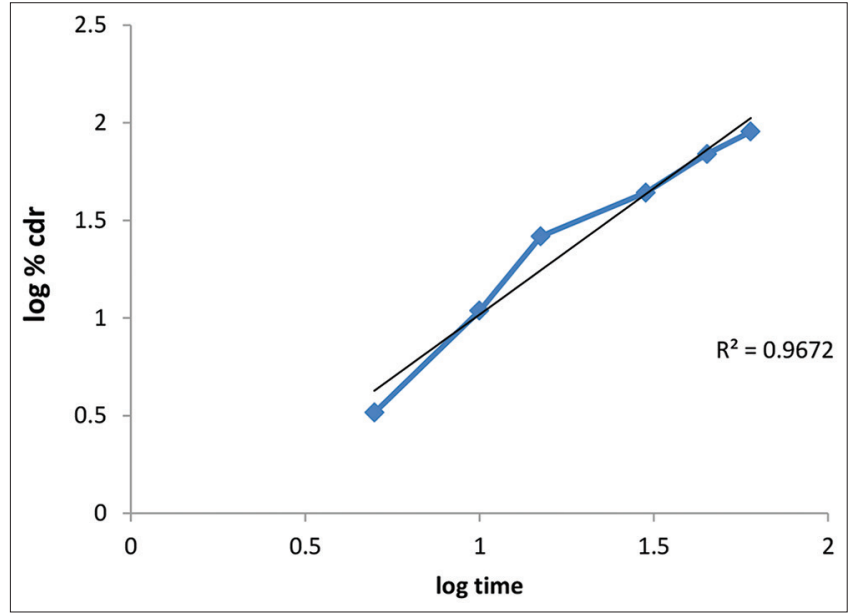

Fig. 19: Korsmeyer-Peppas equation of marketed formulation

Difference factor

It was found to be 13.55 . Thus, it complies with the standard value (Table 12).

Model dependent methods

The dissolution profiles were evaluated depending on the derived model parameters. The model dependent approach included zero order, first order, Higuchi, and Korsmeyer-Peppas model, etc.

\section{Release kinetics}

Release kinetics described the overall release of the drug from the dosage forms. Release kinetics of both final formulation and marketed product was determined using different mathematical models as shown in Tables 13 and 14. In case of zero order $\left(Q_{t}=Q_{0}+K_{0} t\right)$. The graph was plotted in cumulative percentage release versus time and in first order release kinetic $\left(\log C=\log C_{0}-K t / 2.303\right)$. The graph was plotted in log cumulative percentage of drug remaining versus time. For Higuchi model kinetics $\left(\mathrm{Q}=\mathrm{K}_{\mathrm{H}} \times \mathrm{t}^{1 / 2}\right)$, the graph was plotted in cumulative percentage of drug versus square root of time and for the KorsmeyerPeppas $\left(\mathrm{Q} / \mathrm{Q}_{0}=\mathrm{Kt}^{\mathrm{n}}\right)$ model, the graph was plotted in log cumulative percentage of drug released versus log time.

These are graphically enlisted below (Figs. 5-19):

1. Final formulation

- Zero order equation

- First order equation

- Higuchi equation

- Korsmeyer-Peppas equation

2. Marketed formulation

- Zero order equation

- First order equation

- Higuchi equation

- Korsmeyer-Peppas equation 
Final formulation complies with marketed formulation for its release pattern, that is, Higuchi equation (Table 15).

\section{CONCLUSION}

The present work was carried out to develop a novel gel based in situ drug delivery system of omeprazole magnesium. The methodology adopted for preparation of in situ gel solution was very simple and cost effective. It is newer approach to improve easy instillation, residence time and bioavailability and prolong drug release. Nine formulation batches were prepared and subjected for evaluation, namely, floating lag time and in vitro drug release. Results showed that F3 and F6 gave good results for in vitro drug release and floating lag time. Among all the formulation, the F3 and F6 were best formulations. From these two formulations, the best was selected on the behalf of their respective evaluation parameter. F3 and F6 formulations were again formulated and evaluated. Results showed that $\mathrm{F} 6$ formulation gives best results. So, F6 was found to be the best candidate for further study. F6 formulation was evaluated for all parameters, namely, homogeneity, $\mathrm{pH}$, color, floating lag time, floating time, in vitro drug release, and drug content. All the parameters were found to be within the limits. F6 formulation was then compared with the available marketed formulation, that is, OMEZ Insta $20 \mathrm{mg}$ by Dr. Reddy's. Comparison was made in respects, that is, drug content, in vitro drug release. Kinetic modeling was done between both the formulations with respect to model dependent and model independent kinetics. Final formulation complies with marketed formulation for its release pattern, that is, Higuchi equation. Results showed that in situ gel has good floating lag time and floating time that is an essential factor for in situ gel. In vitro drug release was found optimum. The f1 value was 13.55 (similarity or equivalence of two profiles) and f2 value was 51.31 (dissolution profiles are somewhat identical). The developed formulation is a viable alternative conventional solution by virtue of its ability to enhance bioavailability through its longer gastric residence time and ability to sustain drug release as well as the advantage of floating and $\mathrm{pH}$ which minimize the degradation of omeprazole magnesium which is easily degraded by acidic environment.

\section{ACKNOWLEDGMENT}

The authors are thankful to the management and principal of the institute for provide facility for completion of the research work in institute.

\section{AUTHORS CONTRIBUTIONS}

All the authors contributed to the preparation of the final manuscript

\section{CONFLICT OF INTEREST}

No conflict of interest.

\section{AUTHORS FUNDING}

The authors did not receive any funding for this research work.

\section{REFERENCES}

1. Li S, Mirchandani HL, Chien TW. Effect of formulation variables on the floating properties of gastric floating drug delivery system. Drug Dev Ind Pharm 2012;28:783-93.

2. Darekar AB, Patil VA, Gondkar SB. Development and characterization of novel in-situ floating gel of levocetirizine dihydrochloride for oral drug delivery system. Der Pharm Lett 2016;8:188-96.

3. Devault KR, Castell DO. Updated guidelines for the diagnosis and treatment of gastroesophageal reflux disease. Am J Gastroenterol 2015;100:190-200

4. Available from: https://www.pubchem.ncbi.nlm.nih.gov/compound/ Omeprazole-magnesium

5. Kumar R, Singh H, Singh P. Development of UV Spectrophotometric method for estimation of pantoprazole in pharmaceutical dosage forms. J Chem Pharm Res 2017;3:113-7.

6. Edith B. Development and Examination of Solubility Measurement Methods for Drug Solubility Determination. Hungary: Semmelweis University, Department of Pharmaceutical Chemistry, Budapest; 2010.

7. Maharjan R, Subedi G. Formulation and evaluation of floating in situ gel of ranitidine using natural polymers. Int J Pharm Pharm Sci 2014;6:205-9.

8. Chauhan B, Shimpi S, Mahadik A. Preparation and evaluation of floating risedronate sodium gelucire matrices. Acta Pharm Sin B J 2014;54:205-21

9. Basu S, Bandyopadhyay A. Development and characterization of mucoadhesive in situ nasal gel of midazolam prepared with Ficus carica mucilage. Am Assoc Pharm Sci PharmSciTech 2017;3:1223-31.

10. Desai S, Bolton S. A floating controlled release drug delivery system: In vitro-in vivo evaluation. Pharm Res 1992;10:1321-5.

11. Frances S, John T. A review on in situ floating gel of telmesartan. Int J Pharm 2008;3:301-11.

12. Suvakanta D. Kinetic modeling on drug release from controlled drug delivery systems. Actapoloniaepharm Drug Res 2010;67:217-23.

13. Thomas LM. Formulation and evaluation of floating oral in-situ gel of metronidazole. Int J Pharm Pharm Sci 2014;6:205-9. 